\title{
O ESTADO, SEGUNDO O DIREITO INTERNACIONAL ${ }^{1}$
}

\author{
Paulo Emílio Vauthier Borges de Macedo²
}

Sumário: 1 Introdução. 2 A Constituição do Estado e o Direito Internacional. 3 Estado de natureza e Direito Internacional. 4 Considerações Finais. 5 Referências.

\begin{abstract}
Resumo: Este artigo propõe-se a traçar um programa de estudos para trabalhos futuros; nele, procura-se fornecer subsídios para uma espécie de "Teoria Geral do Estado" que leve em consideração não apenas o direito constitucional e/ou a situação jurídica-política interna, mas também o direito internacional. Como regra, os estudos tradicionais deste porte consideram o Estado o pináculo do engenho humano e, assim, ou as suas análises detêm-se dentro das fronteiras nacionais, ou elas aceitam a ideia de que, além destes limites, não pode haver Direito. Estudar o Estado, segundo o direito internacional, tornar-se-ia irrelevante uma vez que as relações internacionais não poderiam engendrar uma ordem jurídica em sentido próprio, porque as nações estariam num verdadeiro estado de natureza. Contudo, estas duas posturas - a que, por comodidade, não avança a análise além das fronteiras nacionais, e a que opta por isso, de maneira consciente - revelam-se equivocadas. Primeiro, o direito internacional pode contribuir bastante para a revisão da clássica tese dos três elementos do Estado, como sugerem recentes casos de sucessão de Estados, e, segundo, negar a juridicidade do direito internacional significa supor que o Direito não pode florescer sem o Estado.
\end{abstract}

Palavras-chave: Sucessão de Estados; analogia doméstica; estado de natureza.

\begin{abstract}
This article attempts to sketch a program of studies for future works: it intends to draw criteria for a "General Theory of State" that would take into account not only Constitutional Law and/or the domestic juridical-political scenery, but International Law as well. As a rule, traditional studies of this kind consider the State the utmost human achievement and, as such, either the argument would contain itself inside of national borders, or they accept the idea that, beyond those limits, there exists a Lawless domain. A study of the State, from the International Law perspective, would become irrelevant since international relations cannot not engender a juridical order in the proper sense, because nations would strive in a true state of nature. Yet, these two opinions - the one that inadvertedly does not advance the argument beyond national borders, and the other chooses the same alternative, but in a conscious manner - are mistaken. First, International Law may indeed deliver to revisit the classic theory of the three State elements, as recent cases of succession of States suggest. Second, denying the juridical essence of International Law implies presupposing a conception that Law cannot blossom without State.
\end{abstract}

Key-words: Succession of States; domestic analogy; state of nature.

\section{INTRODUÇÃO}

Estado e direito internacional sempre foram vistos como antípodas: quando um é ressaltado, isto é feito em detrimento do outro. Se o poder do Estado é enfatizado, coloca-se em dúvida a própria juridicidade do direito internacional, e, ao contrário, uma ênfase na jurisdição internacional implica a redução do poder estatal. De fato, compatibilizar uma concepção absoluta de soberania com a ideia de um Estado responsável e cumpridor de suas obrigações internacionais parece tarefa de Sísifo. Assim, várias foram as tentativas para diminuir o conceito absoluto de

\footnotetext{
${ }^{1}$ Este artigo foi publicado anteriormente nos Cadernos do Programa de Pós-Graduação em Direito PPGDir./UFRGS, v. VI, pp. 98-120, 2007.

2 Professor adjunto de Direito Internacional Público da UERJ e da UFRJ, e-mail: borgesmacedo@hotmail.com
} 
soberania. Contudo, impor limites a um poder que não encontra outro superior (summa potestas superior non recognoscens) significa atentar contra a própria noção de soberania.

A Carta da ONU consagra o princípio da não-intervenção e assegura aos Estados certo domínio reservado, um âmbito de validade material exclusivo do direito nacional, mas estes institutos encontram diversos limites. De fato, há inúmeras normas e organismos internacionais que constrangem a atuação estatal. Se soberania corresponde a um poder sem limites, não há outra alternativa ao Estado senão negar validade ao direito internacional.

As relações entre o Estado e o direito internacional constituem uma questão, em essência, doutrinária. Com isso, não se quer dizer que se trata de matéria de fé, uma convicção de foro interno destituída de consequências práticas. Em 1922, foi celebrada uma convenção germano-polonesa que deveria proteger as minorias naqueles países. E essa convenção foi desrespeitada. Em 1933, a Assembleia Geral da Liga das Nações reúne-se, Bernheim, um judeu habitante da Silésia, pede a palavra e denuncia as "práticas odiosas e bárbaras dos hitleristas a expensas de seus próprios compatriotas refratários ao regime". Ele explica como os nazistas incendeiam as lojas e as casas, violentam as mulheres, assassinam os homens e molestam as crianças, saqueiam as sinagogas, profanam tumbas e lugares sagrados e expulsam famílias inteiras de seus lares. O presidente da sessão concede a palavra ao representante da Alemanha, um certo Joseph Goebbels. A sua resposta está registrada nos anais do princípio da não-intervenção: "Senhores, representantes e presidente. Nós somos um Estado soberano; tudo o que este indivíduo afirmou não vos concerne. Nós fazemos aquilo que queremos dos nossos socialistas, pacifistas e judeus, e não estamos sujeitos ao controle nem da humanidade, nem da SDN.”3 Não procurou negar ou escamotear os fatos, nem alegou a inocência do seu governo.

Os diplomatas daquele encontro ficaram petrificados, mas não por Goebbels e sim por Bernheim. A resolução proveniente daquela sessão foi bastante comedida e se absteve de qualquer condenação: a Liga "confia" que todos seus membros não devem atentar contra os direitos dos homens sob sua jurisdição. A prevalência da soberania sobre os direitos do homem foi bem estabelecida. A Alemanha recebe carta branca sobre como tratar suas minorias, e o plano político

3 BETTATI, Mario. Le Droit d'Ingérence: mutation de l'ordre international. Paris: Odile Jacob, 1996. p. 18. Tradução livre. 
descrito no Mein Kampf pôde ser cumprido. Hitler acreditava que o "respeito pela pessoa humana que todos têm presente nada mais é do que uma invenção das fábulas para se proteger dos mais fortes"4. Neste caso, a Liga preferiu assistir a violação do tratado (bem como, posteriormente, de outros documentos internacionais) a permitir qualquer arranhão na superfície da soberania alemã.

Essa atitude não deve causar surpresa: na sua ampla maioria, a doutrina sempre enfatizou o poder do Estado em detrimento do direito internacional. Os escritores que criaram o conceito de soberania não deixaram espaço para este direito. Consoante Bodin, "a soberania é o poder absoluto e perpétuo de uma república (...) não é limitada nem em poder, nem na responsabilidade, nem no tempo"5. Neste texto, procurar-se-á realizar uma démarche em sentido contrário e colher elementos para uma espécie de "Teoria Geral do Estado" que leve em consideração não apenas o direito constitucional e/ou a situação jurídica-política interna, mas também o direito internacional.

\section{A CONSTITUIÇÃO DO ESTADO E O DIREITO INTERNACIONAL}

Até bem recentemente, o Estado apresentava-se ao direito internacional como uma realidade histórico-social que este nada contribuía para a sua formação. A existência do Estado revelava-se matéria estranha ao direito internacional, o qual se limitava somente a constatar um fato. $\mathrm{O}$ instituto do reconhecimento de Estado possuía, de acordo com a mais aceita doutrina, natureza meramente declaratória: o país preexiste ao reconhecimento dado pelos seus pares. O art. 13 da Carta da OEA consagrou esta concepção: "a existência política do Estado é independente do seu reconhecimento pelos outros Estados.” ${ }^{\mathrm{E}}$ esta posição não parece alterar-se. Consoante a Opinião n. 1 de 29/11/1991 da Comissão de Arbitragem da Conferência pela Paz na Iugoslávia (Comissão Badinter), "a existência ou desaparecimento de um Estado é uma questão de fato, (...) os efeitos do reconhecimento por outros Estados são meramente declaratórios"

Hans Kelsen, mesmo sem concordar com uma natureza puramente

\footnotetext{
4 BETTATI, Mario. Op. cit., p. 19. Tradução livre.

5 BODINO, Juan. Los Seis Libros de la República. Madrid: Aguilar, 1973. pp. 46-48. Tradução livre.

6 ORGANIZAÇÃO DOS ESTADOS AMERICANOS. Carta da Organização dos Estados Americanos. Disponível no sítio oficial da OEA: <http://www.oas.org>. Acesso em maio de 2008.

7 Opinion n. 1. OPINIONS OF THE ARBITRATION COMMITTEE FOR YOUGOSLAVIA. Disponível em <http://www.ejil.org/journal/Vol3/No1/art13.html>. Acesso em maio de 2008. Tradução livre.
} 
declaratória do instituto de reconhecimento de Estado, foi decisivo para difundir a ideia de que a criação de um Estado não consiste num ato jurídico internacional. $\mathrm{O}$ pensamento kelseniano exerceu profunda influência sobre a Escola de Viena, em especial, e toda a teoria jurídica do século XX, em geral. O autor explica a existência de uma determinada ordem jurídica pelo que denomina de "princípio da eficácia". Sabe-se que o professor de Berkeley distingue a validade da eficácia. Uma norma não precisa ser efetivamente cumprida para ser válida. O mesmo, contudo, não se aplica ao ordenamento como um todo. "Cada norma individual perde sua validade quando a ordem total perde sua eficácia como um todo. A eficácia da ordem jurídica como um todo é uma condição necessária para a validade de cada norma individual da ordem." Adiante, explica que o princípio da eficácia constitui uma norma positiva de direito internacional. "A partir da perspectiva do direito internacional, a constituição de um Estado é válida apenas se a ordem jurídica estabelecida com base nessa constituição for, como um todo, eficaz." 8

Isso significa que o direito internacional nada tem a dizer sobre a constituição de um Estado, não impõe qualquer condição. Mas ele vai conferir validade a ordens jurídicas nacionais eficazes. Na teoria kelseniana, isso se revela bastante importante porque o autor considera o Estado uma ordem jurídica parcial dentro do direito internacional. Há, portanto, um elemento de subordinação do Estado em relação àquele direito. Todavia, fora deste contexto, este raciocínio mostra-se destituído de qualquer força. Para aqueles não adeptos do monismo kelseniano, essa assertiva traduz-se pela noção de o direito internacional tão-somente ratificar a existência dos Estados.

Assim, o Estado permanecia um problema apenas para a teoria geral do Estado ou para o direito constitucional. No entanto, alguns acontecimentos parecem autorizar certa margem de discordância. Nos recentes nascimentos de Estados, o direito internacional desempenhou papel relevante na medida em que proveu, direta ou indiretamente, um fundamento jurídico. É o caso do surgimento da Namíbia, em 1990. A ONU pôs fim ao mandato da África do Sul sobre o território, o que eliminou o justo título do governo de Pretória. Em seguida, a Assembleia Geral reconheceu o direito do povo da Namíbia à autodeterminação. A autodeterminação também foi o argumento utilizado para a obtenção do status de Estado pela Micronésia e Palau em,

\footnotetext{
${ }^{8}$ KELSEN, Hans. Teoria Geral do Direito e do Estado. Trad. Luís Carlos Borges. São Paulo:
} Martins Fontes, 1990. pp. 123 e 125. 
respectivamente, 1990 e 1994. Na independência da Eritréia de 1993, há uma justificativa jurídica bastante importante: o destino desta ex-colônia italiana foi decidido na Assembleia Geral, mas a Etiópia não havia respeitado os seus compromissos internacionais desde que assumiu a jurisdição deste território em 1950. A independência do Timor Leste e dos países bálticos recebeu ampla legitimidade do direito internacional, uma vez que haviam sido ocupados de maneira ilícita. 9

Além desses exemplos, houve diversas proclamações de independência que não se beneficiaram de reconhecimento internacional: entre vários outros, a Tchetchênia, o Kosovo, a ilha de Bougainville, Somalilândia e a ilha comorense Anjouan. Não se deve olvidar ainda do estranho caso da Palestina, cujo direito à existência não oferece dúvidas, mas que não consegue obter sua independência. Todos esses fatos possibilitam criar uma distinção entre Estados de jure e Estados de facto: os primeiros reuniriam todas as condições necessárias para formar um Estado e ainda contariam com o respaldo da comunidade internacional. Por este motivo, Marcelo Kohen advoga a ideia de a legalidade perante o direito internacional ser um requisito - além dos três elementos tradicionais, povo, território e governo - para a existência do Estado. ${ }^{10}$

Uma distinção entre Estados de jure e Estados de facto, ab initio, não teria qualquer sentido para os seguidores do princípio da efetividade. Se há, de fato, um Estado, este se torna um Estado de jure também. As situações de fato são assimiladas às situações de direito. Porém, mesmo com a manutenção deste princípio, há determinadas questões legais que só podem ser explicadas com a referida distinção. Apesar da RES/CS/ONU/276/1970, que considerava ilegal a presença da África do Sul na Namíbia, aquele país continuava a ocupar este. A manutenção da ocupação sem justo título gerou à África do Sul responsabilidade internacional. Mas esta não foi a única obrigação internacional do país. Segundo a Corte Internacional de Justiça,

o fato de a África do Sul não possuir mais título válido para administrar o Território não a libera de suas obrigações e responsabilidades internacionais perante outros Estados, no que tange o exercício de seus poderes em relação a este Território. É o controle físico de um território, não a soberania ou a legitimidade do título, que constitui a base da responsabilidade do Estado em razão de atos que afetem outros Estados. ${ }^{11}$

\footnotetext{
9 Cf. KOHEN, Marcelo. Création d'Etats en droit international contemporain. Cours EuroMéditerranéens Bancaja de droit international, v. VI, 2002, pp. 549-550.

${ }^{10}$ Cf. KOHEN, Marcelo. Op. Cit., p. 631.

${ }^{11}$ CORTE INTERNACIONAL DE JUSTIÇA. Advisory Opinion of 21 June 1971. Legal Consequences for
} 
Perceba-se que a Corte em momento algum abdicou do princípio da efetividade; ao afirmar que o controle físico do território constitui a base da responsabilidade do Estado, ela faz deferência a este princípio. Se for aceita a concepção de que a efetividade cria o direito, haverá um paradoxo: o direito internacional considerava a ocupação ilegal, mas esta, de fato, existia, o que gera consequências jurídicas. Não há ocupação ilegal, de acordo com o princípio da efetividade: ou ela é legal e, assim, gera efeitos jurídicos normalmente, ou não existe e, pois, não há nenhuma obrigação jurídica decorrente. A opinião da Corte só faz sentido, se for possível estabelecer uma diferença entre Estados de facto e de jure. Isso significa que o direito internacional não é irrelevante para a criação de um Estado.

Assim, a razão assiste a Kohen, e deve procurar-se um quarto elemento constitutivo do Estado, além dos três tradicionais. Ademais, este elemento deve provir do direito internacional.

Cumpre salientar que a concepção tradicional encontra-se bastante arraigada tanto entre doutrinadores, como nos instrumentos jurídicos internacionais. A Convenção de Montevidéu sobre Direitos e Deveres dos Estados de 1933 a consagra, logo no seu art. $1^{0}$ : população permanente, território determinado, governo e capacidade de entrar em relações com os demais Estados. ${ }^{12}$ Este último elemento pode ser englobado por governo ${ }^{13}$, porque representa um grau de poder deste. À época, preferiu-se não empregar o termo "soberania" por questões políticas, mas é exatamente por isso que se deve entender a expressão "capacidade de entrar em relações internacionais": um Estado legalmente independente (o que reflete a clássica identificação entre soberania e independência realizada por Max Huber no bastante citado caso Palmas de 04/04/1928, no Tribunal Permanente de Arbitragem).

Ainda assim, mostra-se possível "traduzir" os elementos constitutivos do Estado em linguagem jurídica internacional. É o que realiza Kelsen. Para o autor, a palavra "Estado" equivale a uma personificação da ordem jurídica nacional. Estado e

States of the Continued Presence of South Africa in Namibia (South West Africa) Notwithstanding Security Council Resolution 276 (1970). p. 54, § 118. Disponível em <www.icj-cij.org >. Acesso em maio de 2008. Tradução livre.

12 CONVENÇÃO SOBRE DIREITOS E DEVERES DOS ESTADOS. Assinada em Montevidéu, em 26/12/1933 e promulgada pelo Dec. 1570 de 13/04/1937. Disponível em <www.mre.gov.br>. Acesso em maio de 2008.

${ }_{13}$ Cf. KOHEN, Marcelo. Op. Cit., p. 556. 
direito nacional constituem uma só realidade. Assim, território e povo significam, respectivamente, o âmbito de validade espacial e pessoal do ordenamento jurídico nacional, e o governo - que Kelsen substitui pela ideia de "poder" do Estado corresponde à própria validade e eficácia desta ordem nacional. ${ }^{14} \mathrm{O}$ jurista austríaco define os tradicionais elementos constitutivos do Estado pelo Direito.

Importa ressaltar que todos os âmbitos de validade do Estado são limitados pelo direito internacional. Assim, o território é fixado por tratados de fronteira. Se uma norma do Estado for executada fora de seu território, há uma violação ao direito internacional. "O território do Estado é o espaço dentro do qual é permitido que os atos do Estado e, em especial, os seus atos coercitivos, sejam efetuados, é o espaço dentro do qual o Estado, e isso significa, os seus órgãos, estão autorizados pelo direito internacional a executar a ordem jurídica nacional." Por sua vez, o povo encontra-se submetido à ordem jurídica do seu Estado, por vezes, mesmo por condutas praticadas fora do seu território. Ocorre que as sanções não poderão efetivar-se fora do território. "Desse modo, a esfera pessoal de validade da ordem jurídica nacional é determinada pelo direito internacional. Trata-se de uma determinação indireta. Ela resulta da determinação da esfera territorial de validade." ${ }^{15}$

Kelsen também afirma que há outros âmbitos de validade de um ordenamento jurídico; por isso deve haver outros elementos do Estado. São eles: o tempo de vida de um Estado e a sua competência; trata-se, respectivamente, dos âmbitos de validade temporal e material da ordem nacional. Como os demais, o direito internacional regula esses dois âmbitos. Este direito regula a esfera temporal de validade na matéria de sucessão de Estados. Como supramencionado, para o autor, esta questão é marcada pelo princípio da efetividade. A esfera material, por sua vez, também encontra limitações no direito internacional: este não permite que a ordem jurídica nacional possa normatizar qualquer matéria. ${ }^{16}$ Muitas questões escapam ao domínio reservado dos Estados.

Por fim, Kelsen faz o direito internacional limitar o próprio conceito de soberania. No último quartel do século passado, o autor responde, perante a Academia de Direito Internacional da Haia, as teses dualistas de Triepel, segundo as

\footnotetext{
14 Cf. KELSEN, Hans. Teoria Geral do Direito e do Estado, pp. 207, 230 e 249.

15 KELSEN, Hans. Teoria Geral do Direito e do Estado, pp. 208 e 231.

${ }^{16}$ Cf. KELSEN, Hans. Teoria Geral do Direito e do Estado, pp. 217 e 238.
} 
quais o direito internacional e o direito estatal formam ordens jurídicas separadas e distintas. A teoria dualista revela-se bastante simples: a vontade do Estado cria o direito interno, que se aplica aos indivíduos, e a vontade dos Estados combinada (Vereinbarung) gera o direito internacional, que incide sobre as nações. ${ }^{17}$ Direito interno e direito internacional são fruto de fontes diferentes e se destinam a relações distintas.

Para Kelsen, o dualismo mostra-se absurdo porque conduz à própria negação do valor jurídico tanto do direito internacional como de outras ordens nacionais, em virtude da ausência de um mesmo fundamento jurídico. $\mathrm{O}$ autor caracteriza a unidade de um sistema jurídico em razão de todas as regras individuais comungarem da mesma norma fundamental. Esta norma confere, além da unidade, o fundamento de todos os demais comandos de um ordenamento. Uma lei irá pertencer a um determinado ordenamento, se ela foi criada por uma autoridade que recebeu este poder de uma outra lei superior. Esta, por sua vez, pertence ao mesmo ordenamento, se foi criada por outra autoridade que recebeu esta faculdade de uma terceira norma superior. Este raciocínio pode aplicar-se repetidas vezes até que a última norma positiva (do direito estatal) seja a constituição. Acima desta, haverá uma norma hipotética, pressuposta e não posta, chamada Grundnorm (e, com ela, encerra-se o fenômeno jurídico). Ocorre que, tanto o direito estatal, como o direito internacional possuirão apenas uma única norma fundamental. ${ }^{18}$

Segundo o jurista austríaco, duas ordens jurídicas coexistentes só podem estar em relação de coordenação ou de subordinação. Esta estabelece uma relação de hierarquia entre as duas ordens. Já coordenar significa equilibrar dois sistemas equivalentes. Esta tarefa, contudo, implica subordinar ambos a uma terceira ordem, a qual deverá delimitar o domínio de uma e de outra. A subordinação, pois, mostra-se a relação mais importante. E uma ordem será subordinada a outra se possuírem o mesmo fundamento de validade. ${ }^{19}$ Trata-se do caso das relações entre direito

${ }_{17}$ Cf. TRIEPEL, Carl H. Les Rapports entre le Droit Interne et le Droit International. Recueil de Cours de L'Académie de Droit International, tomo I, 1925. p. 85.

${ }^{18}$ Cf. KELSEN, Hans. Les rapports de système entre le droit interne et le droit international public. Recueil de Cours de L'Académie de Droit International, tomo 14, 1926, p. 258. Kelsen afirma que há duas possibilidades para esta unidade: o monismo com prevalência do direito interno ou o monismo com prevalência do direito internacional. Ambas são lógica e juridicamente perfeitas, mas a primeira conduz a uma espécie de "egotismo jurídico"; cada país consideraria o seu próprio direito como o único verdadeiro. Por isso, ele faz uma opção política pela segunda alternativa.

19 Cf. KELSEN, Hans. Les rapports de système entre le droit interne et le droit international public, p. 270. 
internacional e direito interno.

Com base nessas afirmações, Kelsen torna-se capaz de negar a própria ideia de soberania. A teoria da soberania estatal só pode sobreviver num sentido bastante relativizado. O Estado somente pode apresentar-se como poder supremo, superior a qualquer outro, em relação a um determinado agrupamento de indivíduos que ele contém. Quanto a outros grupos, como a população de um Estado estrangeiro, o Estado não é superior, mas apenas - numa acepção negativa - nãosubordinado. Revela-se, portanto, seu igual e independente. Há que se distinguir então dois conceitos de soberania, um interno e outro externo (ou de direito internacional). Ocorre que este raciocínio é contraditório e representa uma simples atenuação da noção de soberania. Se, no seu interior, o Estado é supremo e, para o exterior, ele é independente e igual aos demais Estados, então todos os Estados estão em relação de coordenação e, assim, compreendidos numa ordem superior que delimita o domínio de cada um. Esta ordem é o direito internacional. Num sentido tão relativo de soberania, que permite a existência de uma ordem superior, a noção se transforma numa tautologia: o Estado é soberano apenas em relação àqueles que subordina. Nesta acepção, também o município será soberano. ${ }^{20}$

Tudo o que foi exposto serve para indicar que uma definição de Estado não pode prescindir do direito internacional. Para que se possa continuar a definir o Estado sem elementos do direito internacional, faz-se necessário negar a existência desta ordem.

\section{ESTADO DE NATUREZA E DIREITO INTERNACIONAL}

Os autores que enfatizam a soberania do Estado tendem a negar a existência ou a juridicidade do direito internacional. A inspiração comum é um trecho bastante pequeno do Leviatã, de Thomas Hobbes. Depois de caracterizar o estado de natureza, o filósofo inglês indaga se esta condição já tenha porventura existido ou se constitui somente uma hipótese lógica. Após considerar a guerra civil e a situação de alguns povos selvagens da América como ilustrações deste estado, afirma categoricamente: o estado de natureza sobrevive nas relações entre os Estados.

[De] qualquer modo, em todos os tempos os reis, e as pessoas dotadas de autoridade soberana, por causa de sua independência vivem em constante rivalidade, e na situação e atitude dos gladiadores, com as armas assestadas,

${ }^{20}$ Cf. KELSEN, Hans. Les rapports de système entre le droit interne et le droit international public, p. 260. 
cada um de olhos fixos no outro; isto é, seus fortes, guarnições e canhões guardando as fronteiras de seus reinos, e constantemente com espiões no território de seus vizinhos, o que constitui uma atitude de guerra ${ }^{21}$.

Tal como os homens se encontravam no estado de natureza, uma situação de guerra permanente de todos contra todos, antes do advento do Estado, os países viveriam assim nas suas relações internacionais, em razão da ausência de um poder político mundial. Além disso, por causa da violência generalizada, o estado de natureza hobbesiano, além de não-político, é um cenário pré-jurídico. Perceba-se como o próprio Hobbes exclui a juridicidade do estado de natureza:

Numa tal situação não há lugar para a indústria, pois seu fruto é incerto; consequentemente não há cultivo da terra, nem navegação, nem uso das mercadorias que podem ser importadas pelo mar; não há construções confortáveis, nem instrumentos para mover e remover as coisas que precisam de grande força; na há conhecimento da face da Terra, nem cômputo do tempo, nem artes, nem letras; não há sociedade; e o que é pior do que tudo, um constante temor e perigo de morte violenta.

A descrição prossegue:

Desta guerra de todos os homens contra todos os homens também isto é consequência: que nada pode ser injusto. As noções de bem e de mal, de justiça e injustiça, não podem aí ter lugar. (...) Outra consequência da mesma condição é que não há propriedade, nem domínio, nem distinção entre o meu e o teu (...)..22 (grifo no original).

Assim, são três as características apontadas pelo filósofo de Malmesbury: um estado de guerra permanente, de todos contra todos; a ausência de qualquer empreendimento humano, pois há uma impossibilidade para o trabalho nesse estado, e a inexistência de qualquer forma de Direito, pois não há título de propriedade, nem noção de certo ou errado, permitido ou defeso, lícito ou ilícito. Logo, se não há Direito no estado de natureza, e esta situação subsiste nas relações entre os soberanos, não há direito internacional.

E o que dizer das leis naturais? Elas existem no estado de natureza. Contudo, Hobbes as destitui de qualquer dignidade. Para ele, as leis naturais consistem em simples regras de prudência. "Uma lei da natureza (lex naturalis) é um preceito ou regra geral, estabelecido pela razão, mediante o qual se proíbe a um homem fazer tudo o que possa destruir sua vida ou privá-lo dos meios necessários para preservá-la, ou omitir aquilo que pense poder contribuir melhor para preservá-

\footnotetext{
${ }^{21}$ HOBBES, Thomas. Leviatã. Trad. João Paulo Monteiro e Maria Beatriz Nizza da Silva. 2. ed. São Paulo: Abril Cultural, 1979. p. 77.

${ }^{22}$ HOBBES, Thomas. Leviatã, pp. 76 e 77.
} 
la.”23 Não há nenhuma concepção de alteridade nesta definição; a lei natural hobbesiana não busca estabelecer padrões valorativos para a conduta do homem em relação ao seu semelhante, mas instrui cada indivíduo na maneira mais eficiente de perseguir a sua própria sobrevivência. Desta feita, se, num determinado momento, o cumprimento de alguma das dezenove leis naturais expressas no Leviatã (ou vinte no De Cive) vier a arriscar a autopreservação, será lícito desobedecê-la. Em outras palavras, a lei natural não constitui uma verdadeira lei. ${ }^{24}$ Corresponde a imperativos hipotéticos instrumentais, cálculos utilitários racionais para melhorar a própria vida.

Por esse motivo, quando Hobbes identifica o direito das gentes com a lei natural, ele não quer com isso conceder algum conteúdo ético ao primeiro, mas demonstrar que as relações internacionais são intrinsecamente violentas e conduzem a um estado de guerra permanente.

\begin{abstract}
No que se refere às atribuições de um soberano para com o outro, que estão incluídas naquele direito que é comumente chamado direito das gentes, não preciso aqui dizer nada, porque o direito das gentes e a lei de natureza são uma e a mesma coisa. E qualquer soberano tem o mesmo direito, ao procurar a segurança de seu povo, que qualquer homem privado precisa ter para conseguir a segurança de seu próprio corpo. (grifo do autor). ${ }^{25}$
\end{abstract}

Diversos escritores que negam a existência do direito internacional percorreram o mesmo trajeto. John Austin, por exemplo, afirma haver quatro categorias as quais o vulgo denomina de Direito: o direito divino (ou direito natural), o direito positivo, a moralidade positiva e o direito em sentido metafórico ou figurado. Ele rechaça a primeira do campo da ciência jurídica, visto que ela não pode tornar-se objeto de um estudo científico (o que significa uma investigação que possa ser observada de modo empírico). Apenas o direito positivo merece a atenção do jurista. Trata-se do direito humano estabelecido por uma autoridade política superior aos seus subordinados. $\mathrm{O}$ direito propriamente dito consiste num comando. $\mathrm{O}$ elemento distintivo do direito positivo em relação à moralidade positiva é a idéia de "autoridade política superior". Se uma lei for posta por quem não detém este tipo de poder, ela não poderá diferenciar-se de uma mera opinião. Por fim, o Direito em sentido metafórico corresponde a um emprego inadequado do termo. É o caso das leis causais que regulam o crescimento dos vegetais, ou das "leis" que determinam o comportamento dos animais inferiores. Para Austin, a falta da inteligência e da

\footnotetext{
${ }^{23}$ HOBBES, Thomas. Leviatã, p. 82.

24 Cf. HOBBES, Thomas. Do Cidadão. Trad. Renato Janine Ribeiro. São Paulo: Martins Fontes, 2002. p. 74 .

25 HOBBES, Thomas. Leviatã, p. 210.
} 
vontade importa. 26

A ciência jurídica possui um objeto bastante concreto: ela estuda os comandos que aparecem na relação entre superiores e inferiores; uma relação caracterizada pela obediência habitual que se comprova pela observação simples. No direito internacional, no entanto, não há uma autoridade política superior. Os seus preceitos, pois, não passam da mera opinião dos Estados. ${ }^{27} \mathrm{O}$ estudioso de direito internacional, assim, escreve sobre moralidade positiva.

Tal como Hobbes, em vez de negar, de maneira frontal, a existência do direito internacional, Austin retira-lhe a juridicidade e o equivale a um ordenamento moral. Cabe ressaltar que o pensamento de ambos pressupõe a controversa tese do estatalismo jurídico e sofre, portanto, de todos os ataques que já foram dirigidos a ela. Em apertada síntese, estas críticas podem ser reunidas em dois importantes grupos:

1. Críticas ao monismo jurídico do Estado. $\mathrm{O}$ estatalismo jurídico pressupõe uma doutrina de que somente o Estado produz o Direito e, assim, exclui todas as formas de pluralismo jurídico. O Estado consistiria no único organismo da sociedade autorizado a dizer o Direito. Outras ordens jurídicas, como a de uma empresa ou a canônica, apresentariam uma espécie de “delegação” do poder político para conceder às suas normas alguma validade e, desta maneira, estas organizações estariam, em certa medida, "contidas" dentro da estrutura estatal. Além disso, não haveria nenhuma força legiferante no costume. Por fim, visto que o Estado se mostra fruto de uma construção histórica, sociedades que não se organizam segundo modelos estatais ou não possuiriam Direito ou possuiriam um tipo mais primitivo de Direito.

Essas premissas revelam-se bastante questionáveis. A tese da delegação legislativa a outros ordenamentos assemelha-se mais a uma hipótese lógica que justifica uma determinada concepção do que uma verdadeira descrição. Ela falha em explicar tanto os mecanismos desta delegação, os quais parecem permanecer insubstanciais, como as eventuais contradições entre uma norma de uma ordem delegada com a ordem principal. Ademais, negar juridicidade ao costume significa contrariar toda a tradição jurídica medieval, ao mesmo tempo em que precisa

${ }^{26}$ Cf. AUSTIN, John. The Province of Jurisprudence Determined. 2. ed. London: John Murray, 1861. pp. 1-4. Disponível em <http://www.book.google.com>. Acesso em maio de 2008.

${ }_{27}$ Cf. AUSTIN, John. Op. Cit., p. 126. 
contornar o fundamento de validade mais aceito da common law. Por fim, a idéia de que sociedades não-estatais constituam uma comunidade jurídica primitiva constitui, nas palavras de Michel Virally, "uma grande falta de imaginação" ${ }^{28}$, porque pressupõe que a organização jurídica estatal equivalha ao único caminho de desenvolvimento possível de um ordenamento jurídico; o Estado seria o pináculo da criatividade política humana, o "fim da história" em matéria política.

2. Críticas à noção de que a força cria o Direito. Os autores que afirmam que somente o direito positivo é Direito terminam por concluir também que todo o direito positivo é Direito. Por uma questão de coerência, os escritores positivistas que rechaçam o idealismo de algumas teorias que fundam o Direito na justiça perdem qualquer outro critério de validade do Direito à exceção da própria vontade do Estado. Ocorre que aceitar o voluntarismo estatal significa legitimar todos os atos do legislador, mesmo os mais monstruosos. "Só é admissível fundar-se o direito na vontade estatal se admitirmos por direito a força física." ${ }^{29}$

O maior defeito desse argumento resume-se a uma confusão entre ser (a força) e o dever ser (a norma). A força não pode produzir o Direito porque os dois pertencem a planos ontológicos diferentes. Esta distinção foi repetida ad nauseam por neokantianos, em geral, e por Kelsen, em especial. ${ }^{\circ}$ Por isso, juspositivistas mais sofisticados como este último, quando buscam o fundamento de validade do Direito, introduzem um elemento intermediário antes da força, uma norma hipotética fundamental ou um contrato social (como faz Hobbes). Assim, contornam o problema e conseguem radicar o Direito no próprio direito. Contudo, trata-se de um artifício argumentativo ou uma ideia da razão, e serve para encerrar o domínio da investigação jurídica. Se o pesquisador quiser continuar a sua busca, ele irá deixar o campo especulativo da ciência jurídica. Esta afirmativa funciona como um aviso para encerrar o percurso, porque, se for ignorada, a única resposta que sobra é a força.

Há, ainda, como foi visto, uma teoria estatalista que não nega a juridicidade do direito internacional: o monismo kelseniano. Só que ela destrói o conceito de soberania. Ela aceita a estatalidade do Direito, porém, para conservar a juridicidade do direito internacional, subtrai do Estado aquele elemento que muitos

28 VIRALLY, Michel. El devenir del derecho internacional. México: Fondo de Cultura Económica, 1997. p. 256.

29 BORGES DE MACEDO, Ubiratan. Metamorfoses da Liberdade. São Paulo: IBRASA, 1978. p. 115 .

30 Cf. KELSEN, Hans. Teoria Pura do Direito. Trad. Luís Carlos Borges. 6. ed. São Paulo: Martins Fontes, 1998. p. 64. 
consideram a sua característica mais essencial. Em verdade, o direito internacional não pode existir num mundo de Estados absolutamente soberanos.

Ademais, existe um equívoco nesta “analogia doméstica” hobbesiana. O filósofo inglês afirma que, nas relações entre os soberanos, subiste o estado de natureza. Então, por que não ocorre um pacto entre os Estados para formar um grande "superestado" e deixar o estado de guerra vigente? ${ }^{11}$ No estado de natureza, a situação de insegurança é tamanha que o medo e a razão vão concorrer para a construção do contrato. A resposta parece bastante óbvia: o consenso entre os Estados não é tão amplo como aquele entre os indivíduos; só é possível atingir esferas de consenso em determinadas áreas temáticas. Por isso, o sistema internacional não apresenta um governo mundial, e a cooperação (que é resultado das mesmas motivações do pacto hobbesiano) revela-se mais pontual. Assim, em determinados tópicos (em que ocorre consenso), criam-se instituições jurídicas, as quais se revelam o meio termo entre um governo mundial, fruto de um pacto entre os Estados, e o próprio estado de natureza.

E por que esse consenso não se mostra tão amplo no sistema internacional? Observe-se que Hobbes não admite um meio-termo entre o contrato e o estado de natureza.

Porque divergindo em opinião quanto ao melhor uso e aplicação de sua força, em vez de se ajudarem só atrapalham uns aos outros, e devido a essa oposição mútua reduzem a nada a sua força. E devido a tal não apenas facilmente serão subjugados por um pequeno número que se haja posto de acordo, mas além disso, mesmo sem haver inimigo comum, facilmente farão guerra uns aos outros, por causa de seus interesses particulares. $3^{2}$

Se o consenso não for tão amplo, segundo Hobbes, quando da realização do pacto, os recalcitrantes devem acatar o que a maioria decidir, pois integram a congregação. “Aquele que voluntariamente ingressou na congregação dos que constituíam a assembleia, declarou suficientemente com esse ato sua vontade (e portanto tacitamente fez um pacto) de se conformar ao que a maioria decidir.” Para a minoria, recusar-se a aceitar o pacto equivale a violar esse pacto. Tampouco pode discutir-se a sua pertença à congregação: "E quer faça parte da congregação, quer não faça, e quer seu consentimento seja pedido, quer não seja, ou terá que se submeter a seus decretos ou será deixado na condição de guerra em que antes se encontrava, e na

\footnotetext{
${ }^{31}$ Como o contrato é uma ideia da razão, é preciso entender essa pergunta de forma alegórica.

${ }^{2}$ HOBBES, Thomas. Leviatã, p. 104.
} 
qual pode, sem injustiça, ser destruído por qualquer um.”33

Perceba-se que, nas relações entre os Estados, a falta de consenso ocorre em relação tanto à extensão da adesão entre os membros (que Hobbes resolve em favor da maioria e do pacto), como ao grau dessa adesão (que, segundo o filósofo, não haveria um meio-termo entre o estado civil e o de natureza). Então, por que, no sistema internacional, não houve um consenso com a mesma extensão e no mesmo grau que o ocorrido no estado de natureza entre os homens, se ambos os cenários se caracterizam por um estado de guerra permanente?

Porque as relações entre os Estados não são como as relações entre os indivíduos no estado de natureza. Há uma diferença sutil na base que acaba originando um desenvolvimento posterior bastante distinto. No estado de natureza hobbesiano, os homens são naturalmente iguais.

A natureza fez os homens tão iguais, quanto às faculdades do corpo e do espírito que, embora por vezes se encontre um homem manifestamente mais forte de corpo, ou de espírito mais vivo do que outro, mesmo assim, quando se considera tudo isto em conjunto, a diferença entre um e outro homem não é suficientemente considerável para que qualquer um possa com base nela reclamar qualquer benefício a que outro não possa também aspirar, tal como ele. 34

Nas faculdades do corpo, não há pessoa tão forte que não possa temer uma maquinação ou uma aliança entre os mais fracos. E, nas faculdades do espírito,

\begin{abstract}
a natureza dos homens é tal que, embora sejam capazes de reconhecer em muitos outros maior inteligência, maior eloquência ou maior saber, dificilmente acreditam que haja muitos tão sábios como ele próprios, porque veem sua própria sabedoria bem de perto, e a dos outros homens à distância. Mas isto prova que os homens são iguais quanto a esse ponto, e não que sejam desiguais. Pois geralmente não há sinal mais claro de uma distribuição equitativa de alguma coisa do que o fato de todos estarem contentes com a parte que lhes coube. 35
\end{abstract}

Os Estados, pelo contrário, são bastante desiguais; nem mesmo "considerados todos em conjunto", pode constatar-se a igualdade. Como considerar iguais países como os Estados Unidos e o Haiti? Qual é a igualdade existente entre a China de um bilhão e duzentos milhões de pessoas e a Micronésia de cerca de cem mil habitantes? Os Estados podem ser juridicamente iguais, mas são naturalmente desiguais. Os fatores que geram a desigualdade são vários: economia, tamanho do território, população, força militar, etc. Atente-se para o fato de que essas não são desigualdades quaisquer, como a cor dos olhos ou o formato da face, mas

\footnotetext{
33 HOBBES, Thomas. Leviatã, p. 109.

34 HOBBES, Thomas. Leviatã, p. 74.

35 HOBBES, Thomas. Leviatã, p. 74.
} 
correspondem a assimetrias que afetam a conquista e a manutenção do poder.

Dessa maneira, o estado de insegurança que perpassa o sistema de Estados não se apresenta tal como o existente no estado de natureza hobbesiano, pois não é geral. Enquanto para uns a sensação de temor se revela irrisória, para outros a simples continuidade da existência constitui um favor. Essa diferença ocasiona diferenças de liberdade e de autonomia na condução das políticas externas. Alguns podem, com mais facilidade, impor a sua vontade e ditar as regras para terceiros, outros barganham uma maior autonomia na mera obediência. A analogia doméstica hobbesiana pressupõe que os Estados sejam jurídica e materialmente iguais, o que não são.

Como consequência, o direito internacional, de modo diverso do direito nacional, possui "esferas de juridicidade": em determinadas matérias em que o consenso é maior, suas normas apresentam-se mais eficazes, funcionam mecanismos de solução de controvérsia, com divisão de trabalho e de função, enfim, há uma maior institucionalização. O direito internacional não constitui um todo uniforme. A advertência de Virally revela-se ainda mais presente: não se deve supor que o direito internacional deva evoluir como o direito nacional.

\section{CONSIDERAÇÕES FINAIS}

Este trabalho não pretende ser propositivo. Procurou-se tão-somente demonstrar que, primeiro, os tradicionais elementos constitutivos do Estado não conseguem explicá-lo por inteiro, e, segundo, que a transposição da situação jurídica primordial dos indivíduos para as relações internacionais se apresenta, no mínimo, questionável. Pela argumentação acima exposta, pode chegar-se à conclusão modesta que uma teoria geral do Estado que leva em consideração o direito internacional deverá, de um lado, revisar os elementos constitutivos do Estado e, de outro, rechaçar a analogia com o direito interno - ou, ao menos, adaptá-la para uma realidade de países formalmente iguais, mas materialmente desiguais.

De fato, o poder do Estado e o direito internacional correspondem a dois extremos de uma mesma escala. A insistência num lado ocorre em detrimento do outro. Mas é igualmente verdadeiro que um não pode prescindir do outro. $\mathrm{O}$ problema é que, por um longo tempo, considerou-se que o ponto de equilíbrio se encontrasse mais próximo do poder do Estado. Hoje, no entanto, parece delinear-se um esforço em sentido contrário com as sucessivas transformações por que passa o 
conceito de soberania. ${ }^{36}$

$\mathrm{O}$ art. 2.1 da Carta da ONU consagra o princípio da igualdade soberana de todos os membros. A soberania encontra-se, pois, positivada e, dessa maneira, o poder do Estado constitui uma necessidade da ordem internacional. Mas uma norma, depois de posta em vigor, adquire certa independência dos motivos e das ideias específicas que a engendraram. Episódios como o de Goebbels, em 1933, dificilmente poderão ainda encontrar abrigo sob o referido dispositivo.

\section{REFERÊNCIAS}

AUSTIN, John. The Province of Jurisprudence Determined. 2. ed. London: John Murray, 1861. pp. 1-4. Disponível em <http://www.book.google.com>. Acesso em maio de 2008.

BETTATI, Mario. Le Droit d'Ingérence: mutation de l'ordre international. Paris: Odile Jacob, 1996.

BODINO, Juan. Los Seis Libros de la República. Madrid: Aguilar, 1973.

BORGES DE MACEDO, Ubiratan. Metamorfoses da Liberdade. São Paulo: IBRASA, 1978.

CONVENÇÃO SOBRE DIREITOS E DEVERES DOS ESTADOS. Assinada em Montevidéu, em 26/12/1933 e promulgada pelo Dec. 1570 de 13/04/1937. Disponível em <www.mre.gov.br $>$. Acesso em maio de 2008.

CORTE INTERNACIONAL DE JUSTIÇA. Advisory Opinion of 21 June 1971. Legal Consequences for States of the Continued Presence of South Africa in Namibia (South West Africa) Notwithstanding Security Council Resolution 276 (1970). Disponível em $<$ www.icj-cij.org >. Acesso em maio de 2008.

\section{INTERNATIONAL COMMISSION ON INTERVENTION AND STATE}

SOVEREIGNTY (ICISS) The Responsibility to Protect: Report of the Commission on Intervention and State Sovereignty. Ottawa: International Development Research Centre, dezembro 2001. Disponível em <http://www.iciss-ciise.gc.ca>. Acesso em fevereiro 2006.

HOBBES, Thomas. Leviatã. Trad. João Paulo Monteiro e Maria Beatriz Nizza da Silva. 2. ed. São Paulo: Abril Cultural, 1979.

. Do Cidadão. Trad. Renato Janine Ribeiro. São Paulo: Martins Fontes,

2002.

36 A última delas, em 2001, define soberania como "responsabilidade para proteger" (INTERNATIONAL COMMISSION ON INTERVENTION AND STATE SOVEREIGNTY [ICISS]. The Responsibility to Protect: Report of the Commission on Intervention and State Sovereignty. Ottawa: International Development Research Centre, dezembro 2001. Disponível em <http://www.icissciise.gc.ca>. Acesso em fevereiro 2006). 
KELSEN, Hans. Les rapports de système entre le droit interne et le droit international public. Recueil de Cours de L'Académie de Droit International, tomo 14, 1926.

Teoria Geral do Direito e do Estado. Trad. Luís Carlos Borges. São Paulo: Martins Fontes, 1990.

Teoria Pura do Direito. Trad. Luís Carlos Borges. 6. ed. São Paulo: Martins Fontes, 1998.

KOHEN, Marcelo. Création d'Etats en droit international contemporain. Cours Euro-Méditerranéens Bancaja de droit international, v. VI, 2002, pp.546635 .

OPINIONS OF THE ARBITRATION COMMITTEE FOR YOUGOSLAVIA. Disponível em <http://www.ejil.org/journal/Vol3/No1/art13.html>. Acesso em maio de 2008.

ORGANIZAÇÃO DOS ESTADOS AMERICANOS. Carta da Organização dos Estados Americanos. Disponível no sítio oficial da OEA: <http://www.oas.org > Acesso em maio de 2008.

TRIEPEL, Carl H. Les Rapports entre le Droit Interne et le Droit International. Recueil de Cours de L’Académie de Droit International, tomo I, 1925.

VIRALLY, Michel. El devenir del derecho internacional. México: Fondo de Cultura Económica, 1997. 